\title{
Influence of Temperature, Relative Humidity and Seasonal Variability on Ambient Air Quality in a Coastal Urban Area
}

\author{
Ramasamy Jayamurugan, ${ }^{1}$ B. Kumaravel, ${ }^{1}$ S. Palanivelraja, ${ }^{1}$ and M. P. Chockalingam ${ }^{2}$ \\ ${ }^{1}$ Department of Civil Engineering, Annamalai University, Chidambaram 608 002, India \\ ${ }^{2}$ Civil Engineering, Vel Tech Dr. RR \& Dr. SR Technical University, Avadi, Chennai 600 054, India
}

Correspondence should be addressed to Ramasamy Jayamurugan; jayashree3@yahoo.co.in

Received 31 August 2013; Accepted 29 October 2013

Academic Editor: Ilias Mavroidis

Copyright (C) 2013 Ramasamy Jayamurugan et al. This is an open access article distributed under the Creative Commons Attribution License, which permits unrestricted use, distribution, and reproduction in any medium, provided the original work is properly cited.

\begin{abstract}
The concentration of air pollutants in ambient air is governed by the meteorological parameters such as atmospheric wind speed, wind direction, relative humidity, and temperature. This study analyses the influence of temperature and relative humidity on ambient $\mathrm{SO}_{2}, \mathrm{NO}_{\mathrm{x}}, \mathrm{RSPM}$, and SPM concentrations at North Chennai, a coastal city in India, during monsoon, post-monsoon, summer, and pre-monsoon seasons for 2010-11 using regression analysis. The results of the study show that both $\mathrm{SO}_{2}$ and $\mathrm{NO}_{\mathrm{x}}$ were negatively correlated in summer $\left(r^{2}=0.25\right.$ for $\mathrm{SO}_{2}$ and $r^{2}=0.15$ for $\left.\mathrm{NO}_{\mathrm{x}}\right)$ and moderately and positively correlated $\left(r^{2}=0.32\right.$ for $\mathrm{SO}_{2}$ and $r^{2}=0.51$ for $\mathrm{NO}_{\mathrm{x}}$ ) during post-monsoon season with temperature. RSPM and SPM had positive correlation with temperature in all the seasons except post-monsoon one. These findings indicate that the influence of temperature on gaseous pollutant $\left(\mathrm{SO}_{2} \& \mathrm{NO}_{\mathrm{x}}\right)$ is much more effective in summer than other seasons, due to higher temperature range, but in case of particulate, the correlation was found contradictory. The very weak to moderate correlations existing between the temperature and ambient pollutant concentration during all seasons indicate the influence of inconstant thermal variation in the coastal region. Statistically significant negative correlations were found between humidity and particulates (RSPM and SPM) in all the four seasons, but level of correlation was found moderate only during monsoon $\left(r^{2}=0.51\right.$ and $\left.r^{2}=0.41\right)$ in comparison with other three seasons and no significant correlation was found between humidity and $\mathrm{SO}_{2}, \mathrm{NO}_{\mathrm{x}}$ in all the seasons. It is suggested from this study that the influence of humidity is effective on subsiding particulates in the coastal region.
\end{abstract}

\section{Introduction}

Industrial revolution started 200 years ago, and its consequences to human beings were recognized at the middle of 20th century. Even before epidemiological studies confirmed the existence of association between air pollution and human health, laws have been proposed to control the burning of fuels in London. Prior to 1981, there were no specific standards for Ambient Air Quality (AAQ) in India, and after enforcement of Air (Prevention and Control of Pollution) Act 1981, the first Ambient Air Quality standards were adopted in November 1982 and revised in April 1994 and again in November 2009 [1].

Air pollutants are being let out into the atmosphere from a variety of sources, and the concentration of pollutants in the ambient air depends not only on the quantities that are emitted but also the ability of the atmosphere, either to absorb or disperse these pollutants. Understanding the behavior of meteorological parameters in the planetary boundary layer is important because atmosphere is the medium in which air pollutants are transported away from the source, which is governed by the meteorological parameters such as atmospheric wind speed, wind direction, and temperature [2].

The pollution concentration in an urban area is a function of mixing depth, wind speed, and physical size of the city. The average wind speed varies more or less from place to place, from month to month and from morning to afternoon [3]. The seasonal variation is also influencing the concentration of pollution. The concentration of particulate pollutants during winter was higher than that in other seasons, irrespective of the monitoring sites at urban region of Kolkata (India), because of the longer residence time of particulates in the 
atmosphere during winter due to low winds and low mixing height [4]. The influence of seasonal variation on air pollutants concentration in Haridwar (India) was observed that the concentrations of air pollutants were high in winter in comparison to summer or monsoon seasons [5].

Dominick et al. [6] studied the influence of meteorological parameters such as temperature, relative humidity, and wind speed on a daily average computation of $\mathrm{PM}_{10}$ and $\mathrm{NO}_{2}$ at three selected stations in Malaysia and found that the temperature has a positive correlation to the concentration of $\mathrm{PM}_{10}$ but a negative correlation to relative humidity for all three stations. Zaharim et al. [7] studied the interaction between the particulate and temperature and found positive correlation in Malaysia. The associations between meteorological parameters and particulates were studied and found that the increase of rain fall and humidity establishes negative correlation with $\mathrm{PM}_{10}$ and the wind speed inducing the increment of average $\mathrm{PM}_{10}$ concentration in Kathmandu valley in Nepal [8]. The particulate matter level in the ambient air is affected by the variation in source strength and meteorological conditions such as relative humidity, precipitation, and wind speed and its direction in Morogoro, Tanzania [9].

Coastal atmospheric conditions widely vary from those over-inland due to the land sea interface, temperature contrast, and the consequent development of local circulations [10]. Strong land breeze was observed about 6.00AM and it was neutralized between 9.00AM and 10.0AM at west coast of Korean peninsula. The sea breeze achieved its maximum strength at 3.00 PM, and the energy of sea breeze deceases with decrease of solar radiation. Further the vortex depth of $350 \mathrm{~m}$ was obtained in the early morning and about $1000 \mathrm{~m}$ around 3.00PM and the penetration length of sea and land breeze were $25-30 \mathrm{~km}$ and the suction length of sea and land breeze were about $15-20 \mathrm{~km}$ and $10-15 \mathrm{~km}$ according to Pokhrel and Lee, [11].

Chennai is a metropolitan city located on the south eastern coast of India, influenced by the coastal atmospheric conditions. The 88 number of industrial clusters in India have been identified as polluted hotspots by the Government of India and Manali of North Chennai is one among them. This study examines the influences of temperature and relative humidity on concentration variation of sulphur di oxide $\left(\mathrm{SO}_{2}\right)$, nitrogen oxides $\left(\mathrm{NO}_{\mathrm{x}}\right)$, total suspended particulate matter (SPM), and respirable suspended particulate matter (RSPM) in North Chennai air basin, with respect to seasonal variation for 2010-2011.

\section{Material and Methods}

2.1. Description of Study Area. Chennai is one of the four major metropolitan cities, located on the south east coast of India. The city is $25.6 \mathrm{~km}$ in length and extends inland to about $11 \mathrm{Km}$ and the total area is $174 \mathrm{Km}^{2}$. The geographical coordinates of the study area are $13^{\circ} 10^{\prime} 04^{\prime \prime} \mathrm{N}$ latitude and $80^{\circ} 15^{\prime} 43^{\prime \prime} \mathrm{E}$ longitude and it is located at an average altitude of 6.7 metres from the sea level [12]. The central Chennai is the commercial hub, and the south and west Chennai are mostly residential areas. North Chennai is the base for petrochemical industries, refinery, fertilizer, and thermal power plants. The northern coast of state Tamil Nadu experiences summer from April to June, followed by pre-monsoon season from July to September. The periods October to December are the Monsoon season and post-monsoon period is from January to March [13]. The study area experienced heavy precipitation and cyclone between October and December during Northeast monsoon.

2.2. Meteorological, Ambient Air Quality Data, and Analysis. The Tamil Nadu State Pollution Control Board is operating three Continuous Ambient Air Quality Monitoring Stations (CAAQS) in the study area. One continuous monitoring station is located in Manali, and another one is at Kathivakkam and the third one is at Thiruvotriyur. (Please see Figure 1).

The concentration levels of pollutants in the ambient air such as sulphur di oxide $\left(\mathrm{SO}_{2}\right)$, nitrogen oxides $\left(\mathrm{NO}_{\mathrm{x}}\right)$, total suspended particulate matter (SPM), and respirable suspended particulate matter (RSPM) are being monitored by the State Pollution Control Board. Data related to ambient air quality were obtained from the State Pollution Control Board for this study. The meteorological parameters such as wind speed, wind direction, temperature, and relative humidity were obtained from the Indian Meteorological Department (IMD). In the present study, regression analysis procedure was attempted.

The maximum and minimum monthly average concentrations, during the period from July 2010 to June 2011, varied between $36.3 \mu \mathrm{g} / \mathrm{Nm}^{3}$ and $8.1 \mu \mathrm{g} / \mathrm{Nm}^{3}$ for $\mathrm{SO}_{2}, 50.3 \mu \mathrm{g} / \mathrm{Nm}^{3}$ and $11.7 \mu \mathrm{g} / \mathrm{Nm}^{3}$ for $\mathrm{NO}_{\mathrm{x}}, 309 \mu \mathrm{g} / \mathrm{Nm}^{3}$ and $29 \mu \mathrm{g} / \mathrm{Nm}^{3}$ for $\mathrm{RSPM}$, and $46 \mu \mathrm{g} / \mathrm{Nm}^{3}$ to $585 \mu \mathrm{g} / \mathrm{Nm}^{3}$ for SPM, respectively.

The maximum and minimum concentration level of sulphur di oxide $\left(\mathrm{SO}_{2}\right)$ nitrogen oxides $\left(\mathrm{NO}_{\mathrm{x}}\right)$, total suspended particulate matter (SPM), and respirable suspended particulate matter (RSPM) recorded at the Manali, Kathivakkam and Thiruvottiyur Continuous Ambient Air Quality Monitoring Stations during pre-monsoon, monsoon, post-monsoon, and summer season from July 2010 to June 2011 are presented Table 1 .

\section{Results and Discussion}

3.1. Influence of Temperature on Concentration of Pollutants. The predominant characteristic of atmosphere is its unceasing change. The temperature recorded in the study area ranged between $21^{\circ} \mathrm{C}$ and $33.2^{\circ} \mathrm{C}$ during monsoon, $21^{\circ} \mathrm{C}$ and $33.4^{\circ} \mathrm{C}$ during post-monsoon, $29^{\circ} \mathrm{C}-37.2^{\circ} \mathrm{C}$ during summer and $25.2^{\circ} \mathrm{C}-36.2^{\circ} \mathrm{C}$ during pre-monsoon seasons. The minimum temperature of $21^{\circ} \mathrm{C}$ was recorded during January 2011 and maximum of $37.2^{\circ} \mathrm{C}$ during May 2011. The monthly maximum and minimum temperature recorded from July-2010 to June 2011 are depicted graphically in Figure 2.

The vertical distribution of temperature in the atmosphere varies with season and location in latitude and longitude, as well as from day to night. The temperature variations and its influence on concentrations of $\mathrm{SO}_{2}, \mathrm{NO}_{\mathrm{x}}, \mathrm{RSPM}$, and $\mathrm{SPM}$ in the ambient air were analyzed for monsoon, postmonsoon, summer and pre-monsoon seasons, and graphs are 


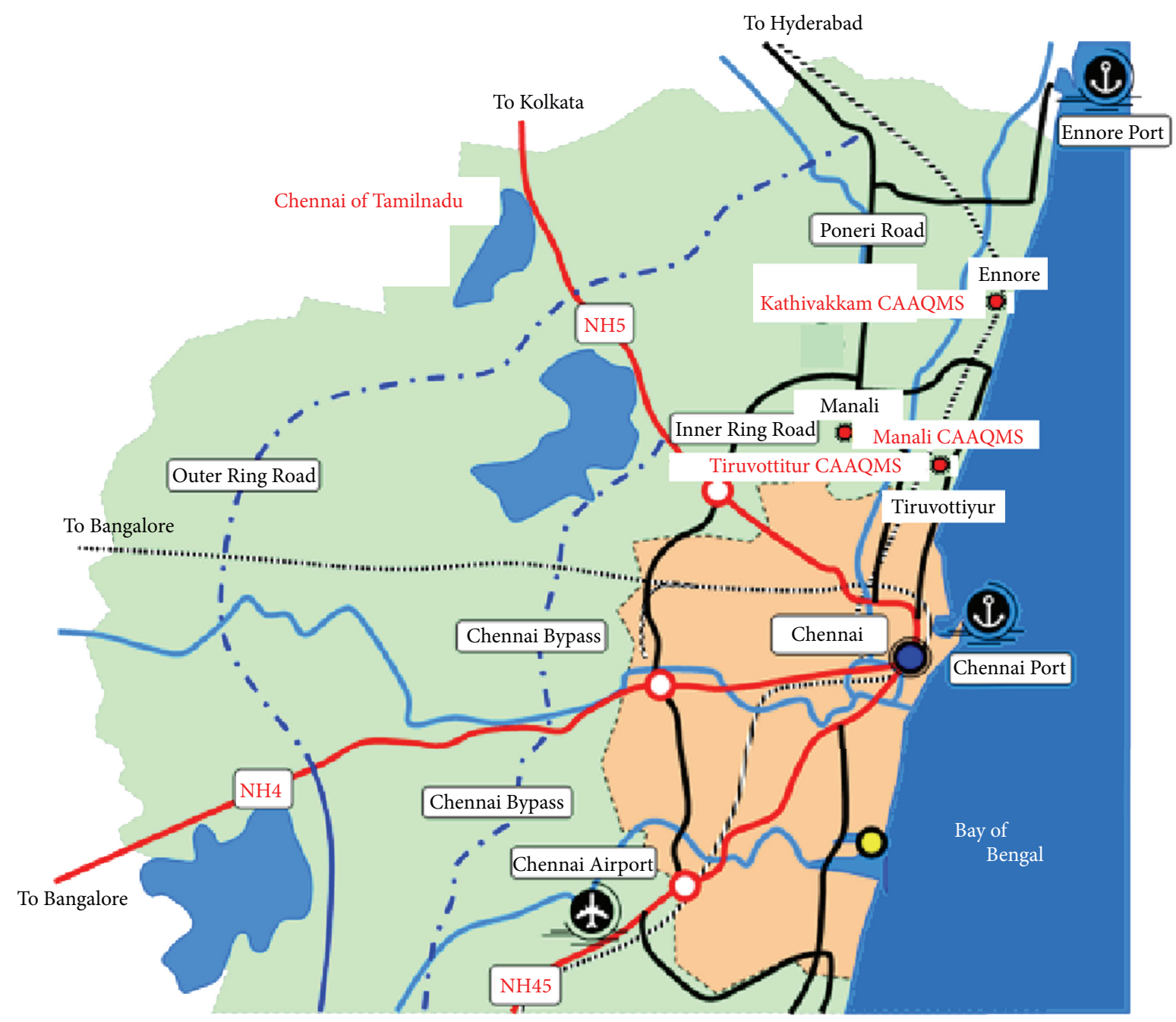

FIGURE 1: Description of the study area.

TABLE 1: Range of pollutant concentrations indicating season wise trend.

\begin{tabular}{|c|c|c|c|c|c|c|c|c|c|}
\hline \multirow{2}{*}{ Pollutants } & \multirow{2}{*}{$\begin{array}{l}\text { Continuous } \\
\text { monitoring } \\
\text { station }\end{array}$} & \multicolumn{2}{|c|}{ Pre-monsoon season } & \multicolumn{2}{|c|}{ Monsoon } & \multicolumn{2}{|c|}{ Post-monsoon season } & \multicolumn{2}{|c|}{ Summer season } \\
\hline & & $\underset{\mu \mathrm{g} / \mathrm{Nm}^{3}}{\operatorname{Min}}$ & $\underset{\mu \mathrm{g} / \mathrm{Nm}^{3}}{\operatorname{Max}}$ & $\underset{\mu \mathrm{g} / \mathrm{Nm}^{3}}{\operatorname{Min}}$ & $\underset{\mu \mathrm{gax} / \mathrm{Nm}^{3}}{\operatorname{Max}}$ & $\underset{\mu \mathrm{g} / \mathrm{Nm}^{3}}{\operatorname{Min}}$ & $\underset{\mu \mathrm{g} / \mathrm{Nm}^{3}}{\operatorname{Max}}$ & $\underset{\mu \mathrm{g} / \mathrm{Nm}^{3}}{\operatorname{Min}}$ & $\underset{\mu \mathrm{gax} / \mathrm{Nm}^{3}}{\operatorname{Max}}$ \\
\hline \multirow{3}{*}{$\mathrm{SO}_{2}$} & Kathivakkam & - & - & - & - & - & 36.3 & - & 27.6 \\
\hline & Manali & - & & 8.6 & - & - & - & - & - \\
\hline & Thiruvottiyur & 8.1 & 17.4 & - & 15.7 & 8.1 & - & 8.5 & - \\
\hline \multirow{3}{*}{$\mathrm{NO}_{\mathrm{x}}$} & Kathivakkam & - & - & - & - & 11.9 & - & - & - \\
\hline & Manali & - & - & 11.8 & - & - & - & - & - \\
\hline & Thiruvottiyur & 12.5 & 30.8 & & 23.1 & - & 33.1 & 11.7 & 50.3 \\
\hline \multirow{3}{*}{ RSPM } & Kathivakkam & 29 & - & 31 & - & - & - & - & 309 \\
\hline & Manali & - & - & - & - & - & 225 & - & - \\
\hline & Thiruvottiyur & - & 243 & - & 292 & 40 & & 35 & \\
\hline \multirow{3}{*}{ SPM } & Kathivakkam & 46 & 386 & 72 & 298 & - & 372 & - & 565 \\
\hline & Manali & 46 & & - & - & - & 372 & - & - \\
\hline & Thiruvottiyur & - & - & - & - & 103 & & 76 & - \\
\hline
\end{tabular}


TABLE 2: Correlation coefficient and the regression equation between temperature and pollutants.

\begin{tabular}{|c|c|c|c|c|c|c|c|c|c|}
\hline \multirow{2}{*}{ Season } & \multirow{2}{*}{$\begin{array}{l}\text { Temperature } \\
\text { range in }{ }^{\circ} \mathrm{C}\end{array}$} & \multicolumn{2}{|r|}{$\mathrm{SO}_{2}$} & \multicolumn{2}{|r|}{$\mathrm{NO}_{\mathrm{x}}$} & \multicolumn{2}{|r|}{ RSPM } & \multicolumn{2}{|c|}{ SPM } \\
\hline & & $r^{2}$ & Equation & $r^{2}$ & Equation & $r^{2}$ & Equation & $r^{2}$ & Equation \\
\hline $\begin{array}{l}\text { Monsoon } \\
\text { season }\end{array}$ & $21-33.2$ & 0.11 & $\mathrm{SO}_{2}=-0.11 T+14.25$ & 0.01 & $\mathrm{NO}_{\mathrm{x}}=-0.042 T+17$ & 0.53 & $\mathrm{RSPM}=8.25-115.9$ & 0.45 & $\begin{array}{c}\text { SPM } \\
=13.55-189.7\end{array}$ \\
\hline $\begin{array}{l}\text { Post- } \\
\text { monsoon } \\
\text { season }\end{array}$ & $21-33.4$ & 0.32 & $\mathrm{SO}_{2}=0.69 T-5.3$ & 0.51 & $\mathrm{NO}_{\mathrm{x}}=0.90 T-4.85$ & 0.03 & $\mathrm{RSPM}=-1.41 T+146.2$ & 0.16 & $\begin{array}{c}\mathrm{SPM}= \\
-6.15 T+382.1\end{array}$ \\
\hline $\begin{array}{l}\text { Summer } \\
\text { season }\end{array}$ & $29-37.2$ & 0.25 & $\mathrm{SO}_{2}=-2.26 T+88.18$ & 0.15 & $\mathrm{NO}_{\mathrm{x}}=-2.25 T+76.63$ & 0.24 & $\mathrm{RSPM}=19.47-539.2$ & 0.26 & $\begin{array}{c}\mathrm{SPM}= \\
29.6 T-767.51\end{array}$ \\
\hline $\begin{array}{l}\text { Pre- } \\
\text { monsoon } \\
\text { season }\end{array}$ & $25.2-36.2$ & 0.17 & $\mathrm{SO}_{2}=0.56 \mathrm{~T}-4.978$ & 0 & $\mathrm{NO}_{\mathrm{x}}=0.0435 T+17.0$ & 0.25 & $\mathrm{RSPM}=15.2 T-379.9$ & 0.38 & $\begin{array}{c}\mathrm{SPM}= \\
32.9 T-821.6\end{array}$ \\
\hline
\end{tabular}

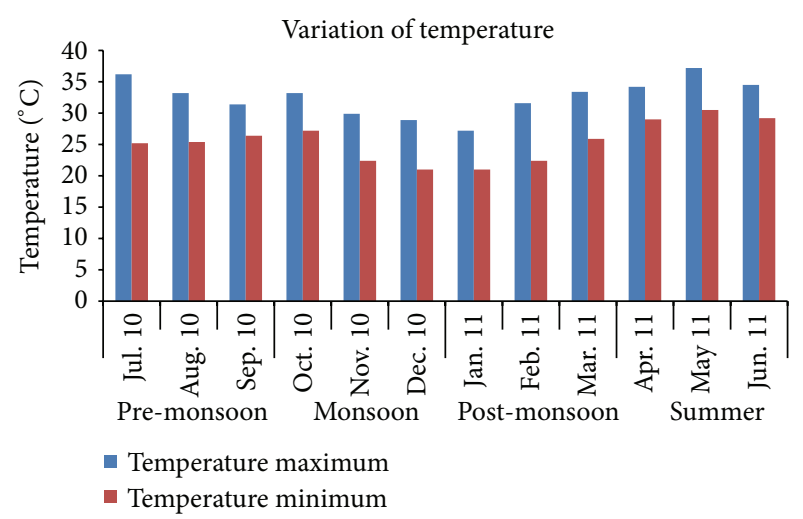

FIGURE 2: Monthly temperature variation between July 2010 and June 2011.

presented in Figure 3 and the results of the regression study are presented in Table 2.

The results of the regression analysis revealed that $\mathrm{SO}_{2}$ and $\mathrm{NO}_{\mathrm{x}}$ have very weak but negative correlation with temperature during summer $\left(r^{2}=0.25\right.$ for $\mathrm{SO}_{2}$ and $r^{2}=0.15$ for $\mathrm{NO}_{\mathrm{x}}$ ). The atmospheric temperature near the earth surface experienced maximum during summer and enhanced the vertical mixing and increase of the mixing height. The uneven heating of land and sea during day time of the summer season occurs quicker, than that of other seasons, because of higher temperature range. The sea breeze starts to flow towards the landward side in the afternoon hours, control the temperature of the coastal region, and minimize the vertical mixing, resulting in weak negative correlation between temperature and $\mathrm{SO}_{2}$ and $\mathrm{NO}_{\mathrm{x}}$ during summer.

This study indicated significant positive correlation between temperature and $\mathrm{SO}_{2}$ and $\mathrm{NO}_{\mathrm{x}}$ during the post-monsoon, $\left(r^{2}=0.32\right.$ for $\mathrm{SO}_{2}$ and $r^{2}=0.51$ for $\left.\mathrm{NO}_{\mathrm{x}}\right)$ and negative correlation during monsoon seasons $\left(r^{2}=0.11\right.$ for $\mathrm{SO}_{2}$ and $r^{2}=0.01$ for $\mathrm{NO}_{\mathrm{x}}$ ). The temperature ranged from $21^{\circ} \mathrm{C}$ to $33.4^{\circ} \mathrm{C}$ and from $21^{\circ} \mathrm{C}$ to $33.4^{\circ} \mathrm{C}$ during monsoon and postmonsoon period, respectively. Though temperature range was almost equal both in monsoon and post-monsoon seasons, the correlations are contradictory because the rain washed out the pollutants during monsoon and minimize the pollutant concentration. The lower temperature range during the post-monsoon periods reduces the vertical mixing and lowering the mixing height, thus resulting significantly in moderate positive correlations of temperature with $\mathrm{SO}_{2}$ and $\mathrm{NO}_{\mathrm{x}}$.

Gamo et al. [14] have studied the annual variation of mixed layer characteristics at New Delhi and found that the mixing height is very low during winter due to very low value of surface sensible heat flux and higher during hot season due to large sensible heat flux from the surface. Heating of earth by the sun induces thermal turbulence during summer and increases the mixing height and found the same reason for negative correlation during summer for the dispersion of $\mathrm{SO}_{2}$ and $\mathrm{NO}_{\mathrm{x}}$.

The RSPM \& SPM had positive correlation with temperature in summer, pre-monsoon, and monsoon season $\left(r^{2}=\right.$ 0.24 for RSPM and $r^{2}=0.26$ for SPM $),\left(r^{2}=0.25\right.$ for RSPM and $r^{2}=0.37$ for SPM $),\left(r^{2}=0.53\right.$ for RSPM, and $r^{2}=0.45$ for SPM) but very weak negative correlation during postmonsoon period $\left(r^{2}=0.03\right.$ for RSPM and $r^{2}=0.16$ for SPM). The study area experienced lower temperatures $\left(24.1^{\circ} \mathrm{C}\right.$ to $29.7^{\circ} \mathrm{C}$ ) during post-monsoon season. Though the temperature range is lower during monsoon, the particulates are subjected to scrubbing process due to the rain, and the possibility of reduction of particulate matter in the atmosphere will be more. During nonrainy days of monsoon, the atmospheric temperature will increase and the concentration of pollutants may also be found to be on higher side, due to the failure of natural scrubbing process. This may be the possible explanation for the moderately positive correlation of RSPM and SPM with temperature in monsoon and pre-monsoon seasons. Bhaskar and Mehta [15] studied effect of meteorological variables including rain fall on particulate concentration and found that the SPM and $\mathrm{PM}_{10}$ had negative correlation with rain fall at Ahmedabad in India.

The probable impact due to rainfall and humidity on particulate in summer and pre-monsoon season could be generally low, when compared to monsoon and post-monsoon seasons, and the positive correlation between temperature and RSPM \& SPM during summer and pre-monsoon season indicates that increase of temperature will always elevate the ambient particulate level. Grija Jayaraman [16] has studied the effects of seasonal variation on the concentrations of 

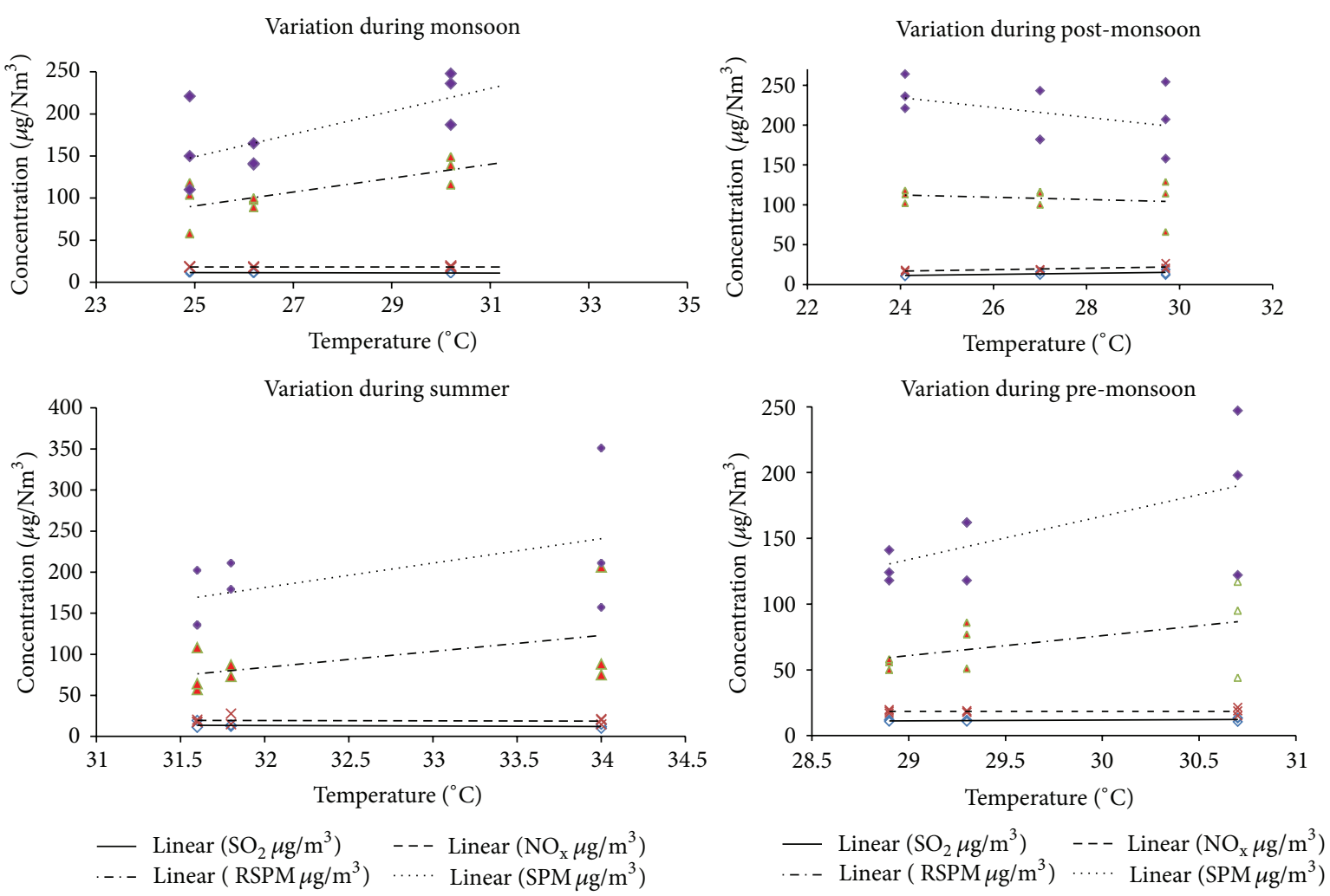

FIGURE 3: Correlation between temperature and $\mathrm{SO}_{2}, \mathrm{NO}_{\mathrm{x}}$, RSPM, and SPM.

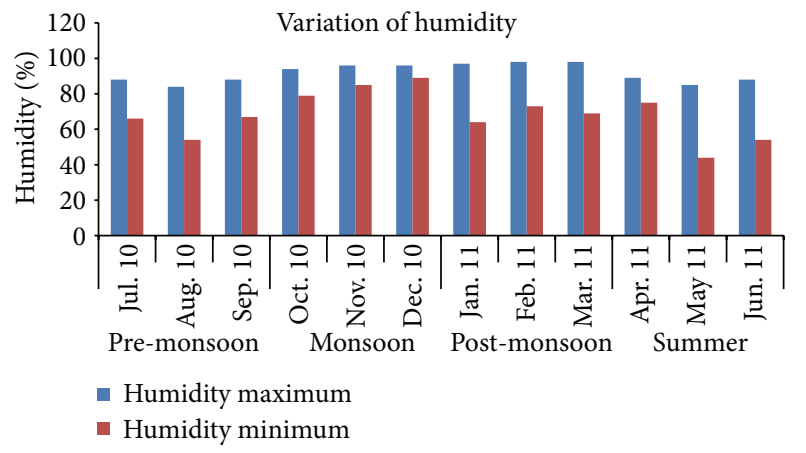

FIGURE 4: Monthly humidity variation between July 2010 and June 2011.

particulate matter in Delhi and reported that the SPM was positively and significantly associated with temperature.

3.2. Influence of Humidity on Concentration of Pollutants. Relative humidity ranged between 79 and 96\% during monsoon, $64-98 \%$ during post-monsoon, 44 and $89 \%$ during summer, and 54 and $88 \%$ during pre-monsoon. The minimum relative humidity of $44 \%$ was recorded in summer and maximum of $98 \%$ during post-monsoon seasons. The monthly maximum and minimum relative humidity in the study area from July 2010 to June 2011 are depicted graphically in Figure 4.
The season wise variations of humidity and its influence on the concentration of $\mathrm{SO}_{2}, \mathrm{NO}_{\mathrm{x}}, \mathrm{RSPM}$, and SPM were analyzed and presented in Figure 5 and the results of the regression analysis are presented in Table 3.

As seen from Table 3 that the $\mathrm{SO}_{2}$ was found to possess positive correlation with humidity during summer, monsoon and post-monsoon, no correlation exists in pre-monsoon seasons. Thought the correlation was positive in summer, monsoon and post-monsoon seasons, the coefficient correlation was only moderate $\left(r^{2}=0.35\right)$ during post-monsoon season. This moderate positive correlation may be due to the formation of inversion layer during post-monsoon period, because the increase of humidity in the atmosphere reduces the amount of solar radiation reaching the earth's surface. The heat from the solar radiation is absorbed by the air, resulting in minimizing atmospheric temperature nearer to the surface of the earth. The air layer nearer to the surface of the earth becomes colder than the upper layers, thus reducing the upgoing air currents and leading to the increase of pollutant concentrations. The same explanation has been indicated by Abed EI-Raoof [17].

As seen in Table 3 that the RSPM \& SPM were negatively correlated with humidity in all the four seasons, coefficient of correlation was found higher only during monsoon season $\left(r^{2}=0.51\right.$ for RSPM and $r^{2}=0.41$ for SPM $)$ in comparison with other three seasons. This might be due to the rate of absorption of particulate in the atmosphere increasing with the increase of humidity. The rain also acts as natural scrubber during monsoon and brings down the particulate level in 

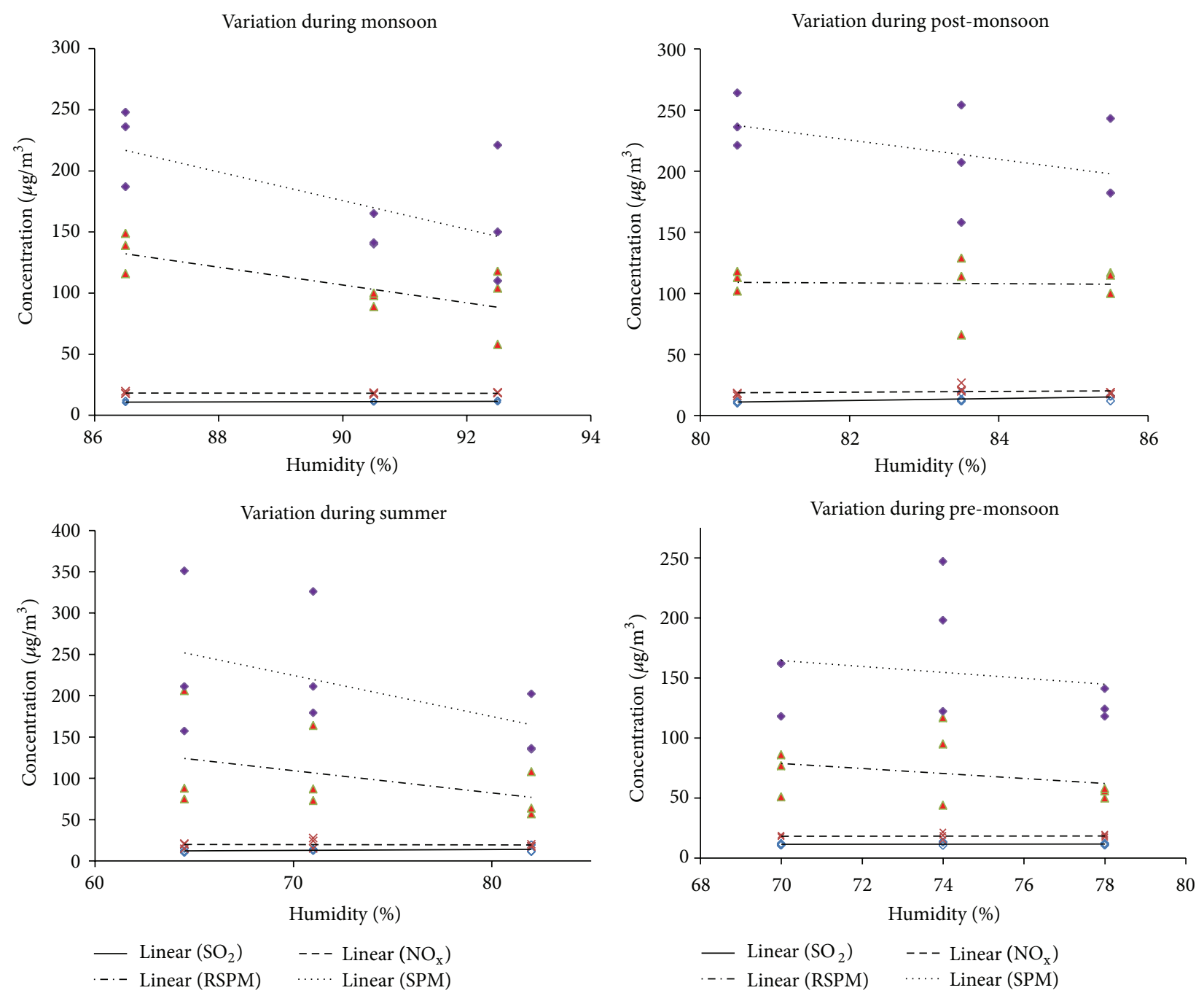

FIGURE 5: Correlation between relative humidity and $\mathrm{SO}_{2}, \mathrm{NO}_{\mathrm{x}}, \mathrm{RSPM}$, and SPM.

TABLE 3: Correlation coefficient and the regression equation between humidity and pollutants.

\begin{tabular}{|c|c|c|c|c|c|c|c|c|c|}
\hline \multirow{2}{*}{ Season } & \multirow{2}{*}{$\begin{array}{l}\text { Humidity } \\
\text { range in \% }\end{array}$} & \multicolumn{2}{|c|}{$\mathrm{SO}_{2}$} & \multicolumn{2}{|c|}{$\mathrm{NO}_{\mathrm{x}}$} & \multicolumn{2}{|c|}{ RSPM } & \multicolumn{2}{|c|}{ SPM } \\
\hline & & $r^{2}$ & Equation & $r^{2}$ & Equation & $r^{2}$ & Equation & $r^{2}$ & Equation \\
\hline $\begin{array}{l}\text { Monsoon } \\
\text { season }\end{array}$ & $79-96 \%$ & +13 & $\begin{array}{c}\mathrm{SO}_{2}= \\
0.109 H+1.42\end{array}$ & 0 & $\begin{array}{c}\mathrm{NO}_{\mathrm{x}}= \\
-0.027 H+20.6\end{array}$ & -51 & $\begin{array}{c}\mathrm{RSPM}= \\
-7.29 H+115.9\end{array}$ & -41 & $\begin{array}{c}\mathrm{SPM}= \\
-11.72 H+1231\end{array}$ \\
\hline $\begin{array}{l}\text { Post- } \\
\text { monsoon } \\
\text { season }\end{array}$ & $64-98 \%$ & +35 & $\begin{array}{c}\mathrm{SO}_{2}= \\
0.7947 \mathrm{H}-52.76\end{array}$ & +5 & $\begin{array}{c}\mathrm{NO}_{\mathrm{x}}= \\
0.330 H-8.01\end{array}$ & -1 & $\begin{array}{c}\text { RSPM }= \\
-0.272 H+130.8\end{array}$ & -22 & $\begin{array}{c}\mathrm{SPM}= \\
-7.894 H+872.9\end{array}$ \\
\hline $\begin{array}{l}\text { Summer } \\
\text { season }\end{array}$ & $44-89 \%$ & +7 & $\begin{array}{c}\mathrm{SO}_{2}= \\
-0.1006 H+5.73\end{array}$ & 0 & $\begin{array}{c}\mathrm{NO}_{\mathrm{x}}= \\
-0.044 H+22.8\end{array}$ & -16 & $\begin{array}{c}\mathrm{RSPM}= \\
-2.68 H+297.4\end{array}$ & -24 & $\begin{array}{c}\mathrm{SPM}= \\
-4.968 H+572.1\end{array}$ \\
\hline $\begin{array}{l}\text { Pre- } \\
\text { monsoon } \\
\text { season }\end{array}$ & $54-88 \%$ & 0 & $\begin{array}{c}\mathrm{SO}_{2}= \\
0.029 H-9.48\end{array}$ & 0 & $\begin{array}{c}\mathrm{NO}_{\mathrm{x}}= \\
0.229 H+16.23\end{array}$ & -8 & $\begin{array}{c}\mathrm{RSPM}= \\
-2.08 H+224.6\end{array}$ & -3 & $\begin{array}{c}\mathrm{SPM}= \\
-2.458 H+336.5\end{array}$ \\
\hline
\end{tabular}

the atmosphere. The influence of humidity and rain on particulate could be high during monsoon, to result in moderate negative correlation during monsoon. Bathmanaban [18] examined the effect on seasons on particulates and found that the particulate concentration is the highest in post-monsoon and winter seasons compared to summer because the percentages of accumulation of coarse particles were relatively higher than those of summer periods.

But in summer, the influence of humidity on particulate could be low because of the lower humidity range, resulting 
the RSPM and SPM to be weakly correlated, and coefficients of correlations are $r^{2}=0.15$ and $r^{2}=0.24$. Jayaraman [16] has studied the effects of seasonal variation on particulates in Delhi and found that SPM concentration was inversely related to relative humidity during all the seasons. Giri et al. [8] have studied the linkage between meteorological process and air pollution in Kathmandu in Nepal and found that the increase of humidity has negative correlation with concentration of particulate matter.

\section{Conclusions}

The influences of temperature and relative humidity on the concentration of pollutants were evaluated for summer, premonsoon, monsoon, and post-monsoon seasons of 2010-2011 using regression analysis and the findings are stated below.

(i) The $\mathrm{SO}_{2}$ and $\mathrm{NO}_{\mathrm{x}}$ were negatively correlated with temperature during summer and monsoon, but positive during pre-monsoon and post-monsoon periods.

(ii) The possible impact due to rain and humidity on the concentration of $\mathrm{SO}_{2}$, and $\mathrm{NO}_{\mathrm{x}}$ during Summer will be low when compared with other seasons.

(iii) The influence of temperature on $\mathrm{SO}_{2}$ and $\mathrm{NO}_{\mathrm{x}}$ is much more effective in summer than in other seasons, due to higher temperature range.

(iv) RSPM and SPM had positive correlation with temperature in summer, pre-monsoon, and monsoon season but very weak negative correlation during post-monsoon. The particulates are subjected to scrubbing process due to the rain, but during nonrainy days of monsoon period, the atmospheric temperature will increase and the concentration of particulate could be on higher side, due to the failure of natural scrubbing process. The positive correlation existing with temperature in summer clearly indicates that the increase of temperature could accelerate concentration of particulates in the ambient air.

(v) Statistically significant negative correlations were found between particulate and humidity and in all of the four seasons, and it is suggested from this study that the influence of humidity is much more effective on subsiding particulates in the coastal region.

\section{Acknowledgment}

The authors are thankful to the authorities of the Tamil Nadu Pollution Control Board, Chennai and authorities of the Indian Meteorological Department, Chennai, for their guidance to carry out this study.

\section{References}

[1] NAAQS, National Ambient Air Quality Standards (NAAQS), Gazette of India, New Delhi, India, 2009.

[2] H. Wexler, “The role of meteorology in air pollution," Air Pollution, vol. 46, pp. 49-61, 1961.
[3] G. C. Holzworth, "Mixing depths wind speed and air pollution potential for selected locations in the United States," Journal of Applied Meteorology, vol. 6, pp. 1039-1044, 1967.

[4] K. Karar, A. K. Gupta, A. Kumar, and A. K. Biswas, "Seasonal variations of $\mathrm{PM}_{10}$ and TSP in residential and industrial sites in an urban area of Kolkata, India," Environmental Monitoring and Assessment, vol. 118, no. 1-3, pp. 369-381, 2006.

[5] A. Chauhan, M. Powar, R. Kumar, and P. C. Joshi, "Assessment of ambient air quality status in urbanization, industrialization, and commercial centers of Uttarakhant (India)," Journal of American Science, vol. 6, no. 9, pp. 565-568, 2010.

[6] D. Dominick, M. T. Latif, H. Juahir, A. Z. Aris, and S. M. Zain, "An assessment of influence of meteorological factors on $\mathrm{PM}_{10}$ and $\mathrm{NO}_{2}$ at selected stations in Malaysia," Sustainable Environment Research, vol. 22, no. 5, pp. 305-315, 2012.

[7] A. Zaharim, M. Shaharuddin, M. J. M. Nor, O. A. Karim, and K. Sopian, "Relationships between airborne particulate matter and meteorological variables using non-decimated wavelet transform," European Journal of Scientific Research, vol. 27, no. 2, pp. 308-312, 2009.

[8] D. Giri, V. Krishna Murthy, and P. R. Adhikary, "The influence of meteorological conditions on $\mathrm{PM}_{10}$ concentrations in Kathmandu Valley," International Journal of Environmental Research, vol. 2, no. 1, pp. 49-60, 2008.

[9] S. L. Mkoma and I. C. Mjemah, "Influence of meteorology on ambient air quality in morogoro Tanzania," International Journal of Environment Science, vol. 1, pp. 1107-1115, 2011.

[10] A. Yerramilli, V. S. Challa, J. Indracanti et al., "Some observational and modeling studies of the atmospheric boundary layer at Mississippi Gulf Coast for air pollution dispersion assessment," International Journal of Environmental Research and Public Health, vol. 5, no. 5, pp. 484-497, 2008.

[11] R. Pokhrel and H. Lee, "Estimation of the effective zone of sea/land breeze in a coastal area," Atmospheric Pollution Research, vol. 2, no. 1, pp. 106-115, 2011.

[12] V. Jayanthi and R. Krishnamoorthy, "Key airborne pollutantsimpact on human health in Manali, Chennai," Current Science, vol. 90, no. 3, pp. 405-413, 2006.

[13] K. Sivaramasundaram and P. Muthusubramanian, "A preliminary assessment of $\mathrm{PM}_{10}$ and TSP concentrations in Tuticorin, India," Air Quality, Atmosphere and Health, vol. 3, no. 2, pp. 95102, 2010.

[14] M. Gamo, P. Goyal, M. Kumari, U. C. Mohanty, and M. P. Singh, "Mixed-layer characteristics as related to the monsoon climate of New Delhi, India," Boundary-Layer Meteorology, vol. 67, no. 3, pp. 213-227, 1994.

[15] B. V. Bhaskar and V. M. Mehta, "Atmospheric particulate pollutants and their relationship with meteorology in Ahmedabad," Aerosol and Air Quality Research, vol. 10, no. 4, pp. 301-315, 2010.

[16] G. Jayaraman, "Seasonal variation and dependence on meteorological condition of roadside suspended particles/pollutants at Delhi," Environmental Science, vol. 2, no. 2, pp. 130-138, 2007.

[17] S. Abed EI-Raoof, "Diurnal and seasonal variation of air pollution at Al-Hashimeya town, Jordan," Jordan Journal of Earth and Environmental Science, vol. 2, no. 1, pp. 1-6, 2009.

[18] S. Bathmanaban, "Analysis of interpretation of particulate matter- $\mathrm{PM}_{10}, \mathrm{PM}_{2.5}$ and $\mathrm{PM}_{1}$ emission from the heterogeneous traffic near an urban roadway," Atmospheric Pollution Research, vol. 1, pp. 184-194, 2010. 

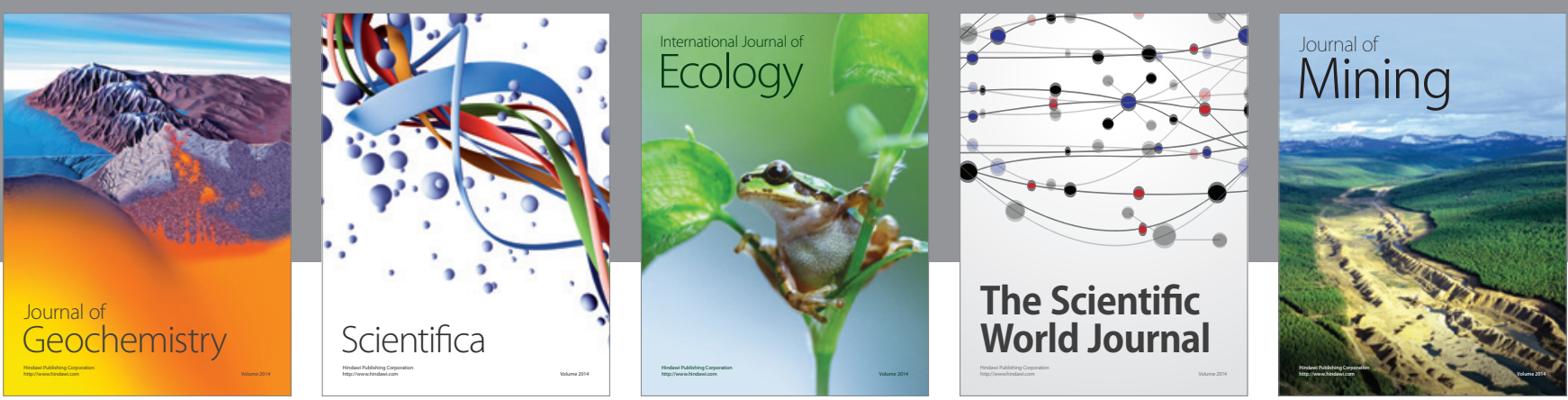

The Scientific World Journal
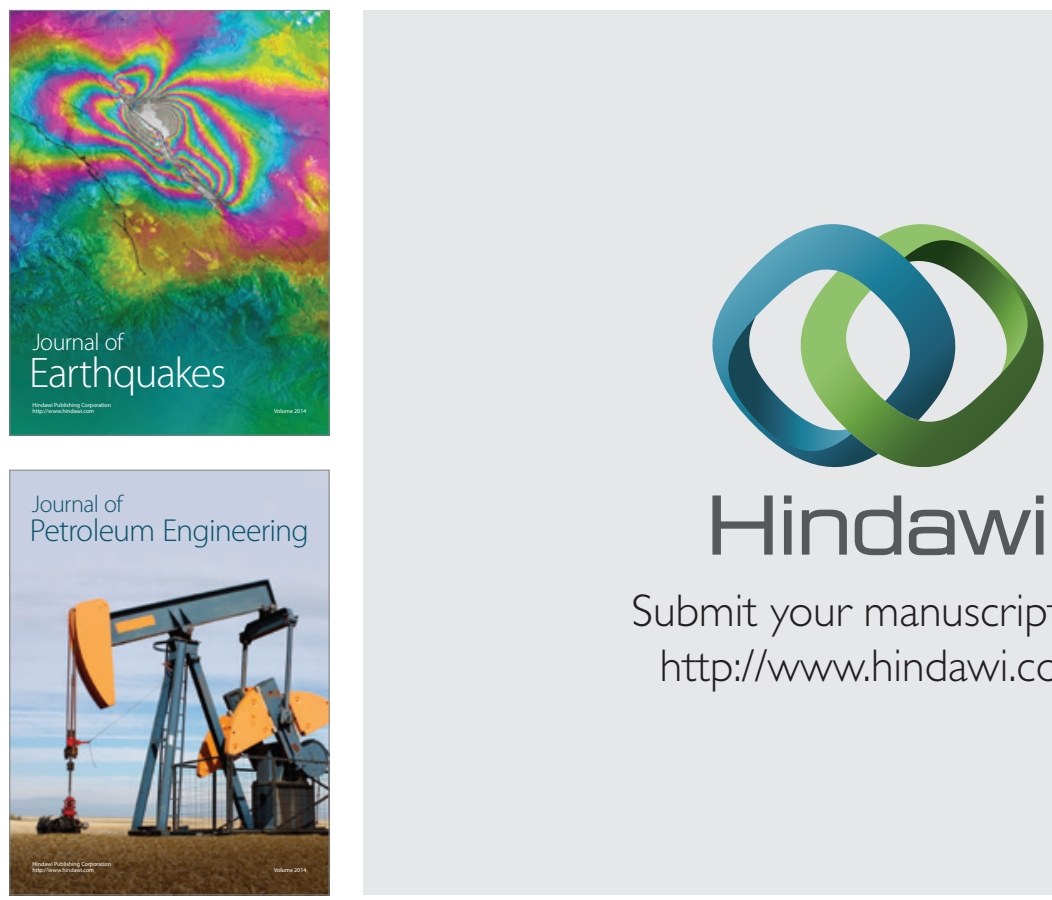

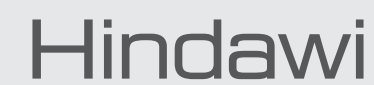

Submit your manuscripts at

http://www.hindawi.com
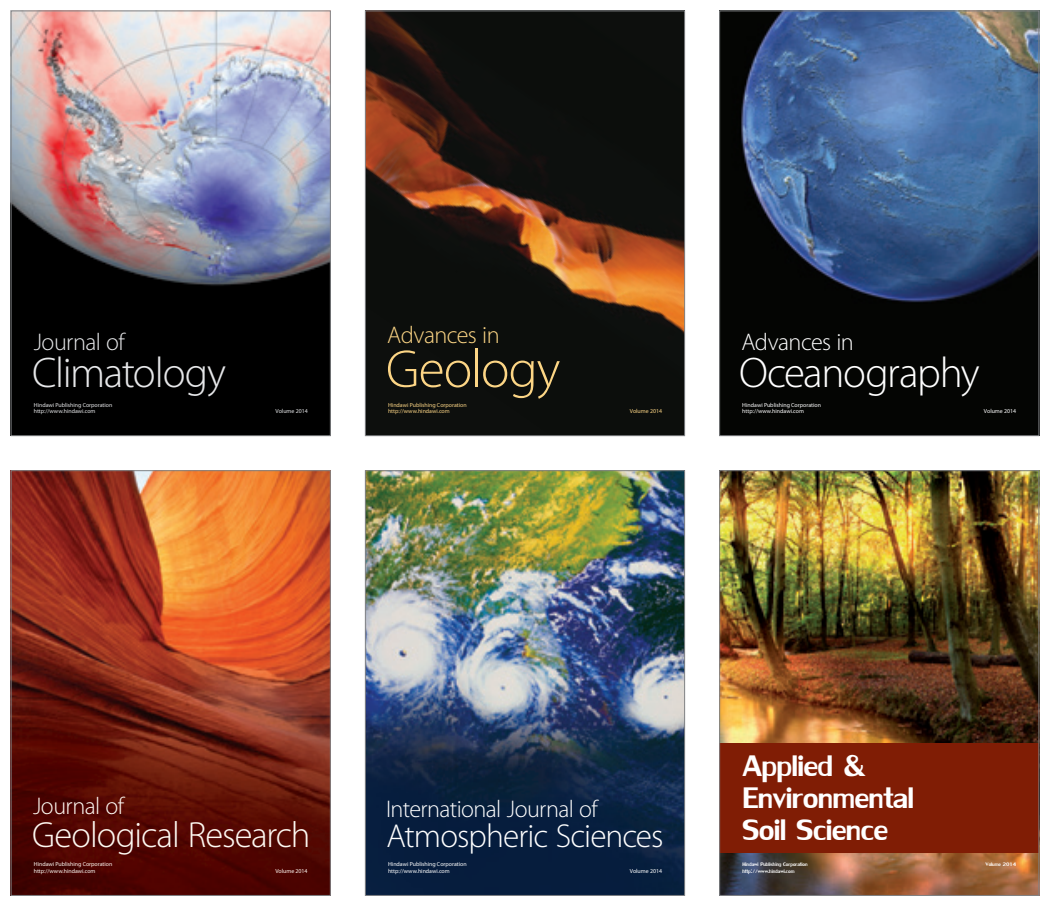
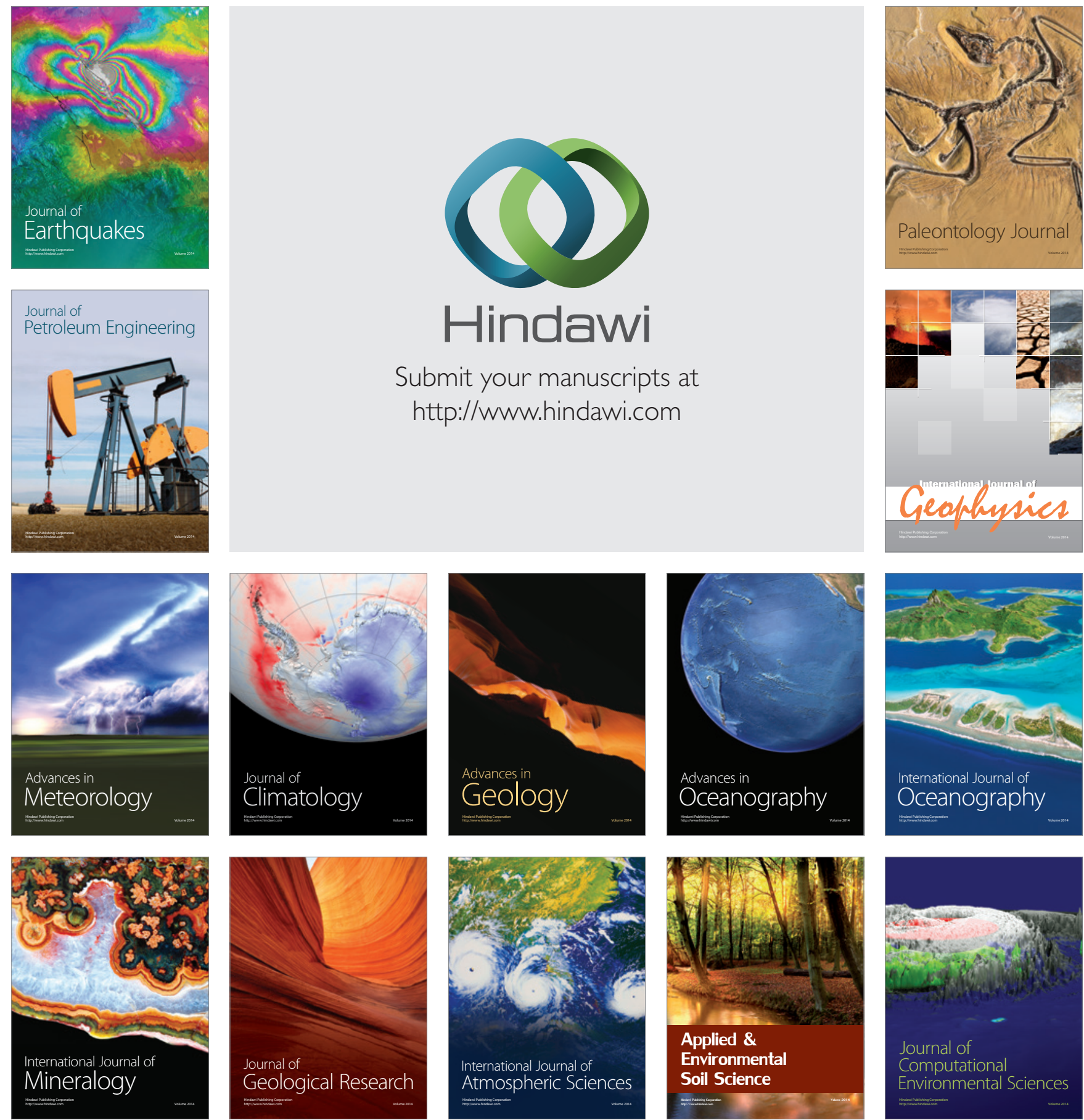